\title{
El endecasilabo blanco: la apuesta por la renovación poética de $G$. M. de Jovellanos
}

\author{
Rodrigo Olay Valdés
}

Oviedo, Instituto Feijoo de Estudios del Siglo XVIII / Ediciones Trea, 2020, 135 pp.

El endecasilabo blanco: la apuesta por la renovación poética de G. M. de Jovellanos, monografía escrita por Rodrigo Olay Valdés, investigador contratado del Instituto Feijoo de Estudios del siglo XviII, es el quinto de los seis Anejos editados desde 2017 dentro de los Cuadernos de Estudios del Siglo XVIII. A diferencia de los denominados Números, compilaciones de artículos, ediciones críticas de textos, reseñas y monográficos de varios autores que no superan las cincuenta páginas y que se articulan en torno a cierta propuesta temática, los más recientes Anejos se constituyen en monografías que giran en torno a las cien páginas o las superan permitiendo a sus autores desarrollar en profundidad objetos de estudio concretos, sin renunciar a la variedad temática de las publicaciones en general. A la difusión de estos trabajos contribuye el hecho de que buena parte de ellos (todos los Anejos y los Números total o parcialmente) se han digitalizado y son descargables gra- tuitamente en la página oficial de la revista (<https://reunido.uniovi. es/index.php/CESXVIII/issue/archives).

Atendiendo ahora al trabajo que nos ocupa, con el objeto principal de comprobar el cumplimiento por parte de Jovellanos de los preceptos métricos promovidos por él respecto del endecasílabo blanco o suelto en sus poesías originales, el estudio de Olay Valdés identifica parámetros que atestiguan la progresiva aplicación de tales premisas en la producción del asturiano, sobre todo en cuanto respecta a la incidencia porcentual de sus cesuras predilectas y de su combinación. Este criterio, objetivamente demostrado, permite a Valdés proponer una datación alternativa de la Elegía a la ausencia de Marina (pp. 79-80), refrendar la ya desmentida asignación de las Sátiras IV y $V$ a la autoría de Jovino (p. 82) o argumentar la probable atribución de la Loa a Campomanes ("Habla la Sabiduría”; pp. 89-90). Dicho 
método, que compara los porcentajes de uso de determinadas formas estróficas y de versificación a lo largo del tiempo, junto con los fines a que se aplica (la cronología de obras y la determinación de la autenticidad de textos atribuidos o no a un autor) concuerdan con los objetivos y la metodología inauguradas por Sylvanus Griswold Morley y Courtney Bruerton en su indispensable Cronología de las comedias de Lope de Vega (ed. original de 1940; trad. al español de 1968), monumental trabajo de investigación pionero de la denominada estilometría, disciplina científicoliteraria en auge en las últimas décadas. Empero, contra la tendencia digital más reciente, el autor de esta monografía prescinde de programas informáticos o softwares mediante los que realizar sus cálculos, estilometría predigital o manual que comparte con su citado precedente (cuya influencia reconoce expresamente en las páginas finales). Ello no va en detrimento de la corrección de los resultados (desglosados claramente en sucesivas tablas), sino que aún los asegura al ser examinados continuamente por el sujeto intérprete durante su elaboración. A continuación, resumimos el contenido de cada uno de los apartados, deteniéndonos sucintamente en algunos aspectos de especial interés.

En las páginas iniciales del primer capítulo "Ideas métricas de Jovellanos" (pp. 9-46), sistematización y contextualización de los preceptos o recomendaciones relativas a la armonía en la poesía deshecha del artificio de la rima, se cita el corpus de cartas y borradores (hasta nueve en total) redactados entre 1773 y 1797 y destinados a cuatro amigos poetas (Carlos González de Posada, Francisco de Paula Caveda y Solares, Juan Meléndez Valdés y Ramón de Posada y Soto), entre otros documentos de menor presencia en el estudio. Previamente, Olay Valdés introduce las obras y corpus utilizados (entre los que sobresalen las Obras completas de J. M. Caso González et al., 1984-2009) con las matizaciones pertinentes. Interesará saber que en el estudio incluye un ilustrativo "Apéndice 2: Listado de poemas empleados en los cómputos y variables tenidas en cuenta" (pp. 118-122). Destaca la aproximación del investigador a la materia por su enfoque crítico y dialéctico, que no evita la discusión de los planteamientos de la crítica anterior, como se observa en la inclusión, en el grupo de poemas atribuidos, y la asignación a la autoría de Jovellanos de la denominada 
Loa a Campomanes ("Habla la Sabiduría") a partir de datos matemáticamente extraídos de la evolución métrica de su poética, composición esa que el estudioso y editor de referencia Caso González (vid. supra) no incluye en su colosal edición. Dicha Loa se halla asimismo transcrita en el "Apéndice 1" del estudio de Olay Valdés. Se suma a la crítica dialéctica de estudios y ediciones recientes de la obra del gijonés el cotejo de prácticas y planteamientos emitidos sobre el verso blanco o suelto por autores anteriores o contemporáneos de Jovino, desde algunos poetas áureos cultivadores del endecasílabo blanco (v.g. Garcilaso de la Vega, Lope de Vega: p. 25; y en un apartado posterior, Juan Boscán, Fernando de Herrera y otros, pp. 53-54) a escritores anglófonos (v.g. el blank verse de John Milton y James Thomson: p. 26), así como la cita de tratadistas cuya preceptiva sigue en parte Jovellanos (el caso de la división en endecasílabo a minore o acentuado en cuarta y a maiore o acentuado en sexta propuesta entre otros por López Pinciano: pp. 3233) y de las tipologías de los preceptistas de nuestro tiempo (v.g. Tomás Navarro Tomás, Antonio Quilis, Domínguez Caparrós o Isabel Paraíso: idem). De esta forma, en su exposición Olay Valdés perfila un amplio entramado de referentes antiguos y modernos que confluyen en las aportaciones teórico-prácticas de Jovellanos como contexto determinante de la comparación.

En ese entorno de confrontación y convergencia de ideas el autor de la monografía articula las razones teóricas de Jovino, entre las que revisten especial importancia, de un lado, la clasificación y jerarquía de cesuras o combinaciones del acento principal del verso y la pausa mínima que le sigue (en sendos subapartados "Un concepto clave: la cesura”: pp. 29-35; y "Jerarquía de las cesuras": pp. 35-38), y del otro, las reglas combinatorias de dichas cesuras (en "Combinación de las cesuras": pp. 38-42). Ya desde el mencionado apartado "Jerarquía de las cesuras", Olay Valdés justifica con un ejemplo el hecho de que originalmente Jovellanos, entre 1777 y 1778, teoriza, pero no practica. Se cierra esta primera sección prefigurando los principios cualitativos ("Otros principios de armonía no cuantitativos": pp. 4226), a diferencia de los precedentes, no relativos a nociones numéricas de armonía, sino a la negación de recurrencias fónicas y otros fenómenos léxico-sintácticos.

Estos y los anteriores planteamientos se certifican, especular- 
mente, en sendos capítulos donde se analizan diacrónicamente como razones prácticas. Así pues, para el análisis de los principios cuantitativos ("Uso del endecasílabo: estudio cuantitativo": pp. 76-94), el estudioso examina doce de los trece textos compuestos en endecasílabos blancos, clasificables en cuatro etapas evolutivas de producción: de 1776 a 1778, de este último año a 1782, de 1786 a 1787 y, finalmente, de 1796 a 1807 . Sigue al estudio de los poemas en endecasílabos sueltos el de textos en endecasílabos rimados, asonantes (pp. 84-86) y consonantes (pp. 87-88), demostrándose sugerentes simetrías o disparidades en su comparación con el endecasílabo suelto. Entre las "Conclusiones" a este capítulo (pp. 88-91) se integran tablas donde se precisa porcentualmente la frecuencia de aparición de qué cesuras en función de la cesura que las precede. Cierran esta sección unos "Esquemas-resumen del uso de las cesuras", donde se desglosan los porcentajes de uso diacrónico de las cesuras y de su combinación entre sí incluyendo los títulos de las obras a que pertenecen. Por otra parte, el análisis de los principios cualitativos se realiza a partir de tres poemas ubicados cada uno en una época de pro- ducción, prestando atención a los criterios negativos introducidos en el capítulo dedicado a la organización de la teoría de Jovellanos, esto es, "Recurrencias fónicas" (pp. 9596), "Rimas internas y asonancias" (pp. 96-97), "Adjetivos y palabras agudas y esdrújulas a final de verso" (p. 100), "Palabras largas" (p. 101) y "Sinalefas violentas" (pp. 101-102).

Entre el primero y los dos últimos capítulos reseñados, se dedica un gran espacio a la exposición del empleo por el autor gijonés de otras estrofas y formas poéticas además de los endecasílabos blancos, en dos capítulos descriptivo o valorativo y cuantitativo, respectivamente. Así pues, "Usos métricos de Jovellanos: descripción” (pp. 47-70) es de especial relevancia sobre todo porque ofrece la primera de las demostraciones de la utilidad forense de la particular minería de textos manual ensayada por Olay Valdés: la confirmación de la autenticidad de tres odas sáficas atribuidas a Jovellanos con base en regularidades rítmicas y de rima (pp. 61-64). Por ańadidura, entre los usos que junto con los endecasílabos sueltos traslucen el pionerismo de Jovino se encuentran, a juicio del investigador, el abandono temprano del heptasílabo vinculado a romanci- 
llos de tono anacreóntico y pastoril (pp. 50-53) y de los epigramas (pp. 68-69) y dos silvas blancas, cuyo uso original inaugura tal vez "la forma más usual en la poesía culta de nuestros días" (pp. 66-67). Completa los comentarios del anterior capítulo el intitulado "Usos métricos de Jovellanos: evolución" (pp. 70-75), que clasifica en diacronía las formas antes descritas en cuantiosas tablas organizadas en función de dos variables, el número de poemas y el de versos. Por último, unas "Reflexiones finales" (pp. 106-114) sintetizan los principales hallazgos y coligen interesantes conclusiones.

En síntesis, el trabajo de Olay Valdés se ocupa, por encima de todo, de dar meticulosa cuenta del valor y la innovación desarrollada por Jovellanos a lo largo de su vida y obra, valiéndose para ello de los criterios, métodos y datos estilométricos que se han esbozado, entre los que destaca el cálculo de la incidencia porcentual de formas de versificación presentadas en diacronía (en esencia, ubicación de la cesura y combinación de endecasílabos con cesura distinta). Por su parte, las conclusiones acerca de la datación y atribución autorial de obras de Jovino prometidas desde la "Introducción" (pp. 5-8) se materializan en puntuales aunque relevantes aportaciones, que tienen como fin invitar a otros investigadores a tomar el testigo, persuadidos por la eficacia probada de su método.

Ignacio Alba Degayón Universidad de Córdoba 